\title{
The Politics of Vaccine Hesitancy: An Ideological Dual-Process Approach
}

Michał Bilewicz and Wiktor Soral

Faculty of Psychology, University of Warsaw

WORD COUNT: 4445

\section{Author Note}

Michał Bilewicz is an Associate Professor of Psychology at the University of Warsaw, Poland, where he chairs the Center for Research on Prejudice. His research interests include conspiracy theories, reconciliation processes, dehumanization, prejudice, and collective moral emotions.

https://orcid.org/0000-0001-5027-1691

Wiktor Soral is an Assistant Professor of Psychology at the University of Warsaw, and a member of the Center for Research on Prejudice. His research interests include psychological antecedents and consequences of hate speech and conspiracy theories. He also studies basic processes related to deprivation of personal control.

https://orcid.org/0000-0003-2557-8071

All authors were involved in all parts of the research equally.

This work was funded by the Polish National Science Centre grant [no 2017/26/E/HS6/00129] awarded to Michał Bilewicz. This work was possible thanks to a grant no. GOSPOSTRATEG-II/0007/2020-00 from Polish National Center for Research and Development.

Correspondence concerning this article should be addressed to Wiktor Soral, Faculty of Psychology, University of Warsaw, Stawki 5/7, 00-183 Warsaw, Poland. Email: wiktor.soral@psych.uw.edu.pl 


\begin{abstract}
Ideological convictions are known to shape attitudes and behaviour in various life domains. Based on existing psychological analyses of political ideology, we use an ideological dual-process approach to explain people's vaccine hesitancy, in which distinguish between authoritarian (RWA) and hierarchical (SDO) facets of conservatism as potential antecedents of vaccination attitudes. In a large international study performed in Germany $(\mathrm{N}=1210)$, Poland $(\mathrm{N}=1209)$, and the United Kingdom ( $N=1222)$, we tested the roles of SDO and RWA in predicting vaccination hesitancy, as well as cross-cultural universality of the the pattern of relationships between political ideologies and attitudes toward vaccines. In all three countries, high SDO was associated with higher vaccine hesitancy, whereas high RWA was associated with lower vaccine hesitancy. These findings contribute to our understanding of the distinctive roles that these two facets of right-wing ideology might play in the domain of public health.
\end{abstract}

Keywords: vaccine hesitancy; RWA; SDO; ideology; authoritarianism 


\section{The Politics of Vaccine Hesitancy: An Ideological Dual-Process Approach}

The global pandemic of COVID-19 has created a pressing need for effective vaccination policies. In many areas, peoples' concerns regarding the COVID-19 vaccines has led to a delay in the vaccination process. This process is known as vaccination hesitancy and has often been regarded as one of the more pressing issue in global public health (Dube et al., 2013; Jarret et al., 2015; MacDonald, 2015). One of the strategic objectives of the WHO's Global Vaccine Action Plan, which aims to prevent epidemic diseases, stated that „individuals and communities to understand the value of vaccines and demand immunization as both their right and responsibility" (GVAP, 2012; p. 38). Regardless of its global importance, people's understanding of the value of vaccination has constituted a recurring problem, and often become a topic of political debate and ideological struggles. This article aims to shed more light on the ideological foundations of vaccine hesitancy.

Psychological research on political ideologies has repeatedly stressed the fundamental character of the liberal-conservative or left-right continuum as a universal dimension organizing people's political views (Jost et al., 2009). At the same time, the utility of this dimension in explaining people's willingness to vaccinate has been limited. American studies have found both higher levels of vaccine hesitancy (Callaghan et al., 2020; Hornsey et al., 2020) and a larger decline in vaccination intentions over six months of the pandemic among conservatives (Fridman et al., 2021). On the other hand, studies conducted in Poland (Kossowska et al., 2021) have found political ideology to be only loosely related to vaccine hesitancy, with conservatives being slightly more sceptical about vaccinations, which was related to greater mistrust toward scientists in that group. In contrast, a large 
study conducted in Spain has found higher scepticism among left-wing supporters (Hornsey et al., 2021), with highly educated radical left-wingers being most sceptical.

The limited predictive power of the left-right political dimension has led scientists to explore alternative political ideologies and beliefs that could play a role in vaccination hesitancy. Some studies have found nationalistic ideology (national narcissism) to be a better predictor of vaccination hesitancy than the left-right dimension (Cisłak et al., in press), while others have suggested the populist politics as a key factor responsible for vaccination hesitancy (Kennedy, 2019).

In the current research, we seek to explain the inconsistent findings regarding the effects of conservatism or right-wing ideologies on vaccination hesitancy by applying the Dual Process Model of Ideology (Duckitt, 2001; Duckitt \& Sibley, 2009). This model distinguishes between two forms of right-wing ideology - one stressing social control and group conformity, and another one stressing the natural character of power and hierarchies. These two facets of right-wing ideology can be conceptualized as well-established psychological constructs: right-wing authoritarianism (RWA; Altemeyer, 1998) and social dominance orientation (SDO; Pratto et al., 1994).

\section{The Normative Aspects of Right-Wing Authoritarianism}

Conformity to traditions and sensitivity to social norms are at the core of authoritarian ideology (Adorno et al., 1951; Altemeyer, 1981; Duckitt, 2001). The original theorists of authoritarianism, when trying to understand this ideological orientation, developed a metaphor of a bicyclist: a person who is "bowing at the top", i.e., is submissive to authorities and established norms, but who is also "kicking at the bottom", i.e., is aggressive toward those who do not submit to authorities and violate the norms (Adorno et al., 1951; p. 291). Authoritarianism is strongly 
associated with the values of social conformity and negation of autonomy (Feldman, 2003; Sibley \& Duckitt, 2008).

Although researchers have long been equating authoritarianism with rightwing, conservative or even fascist ideologies (Adorno et al., 1951; Jost et al., 2003), there is an increasing evidence that authoritarianism is not only distinctive from conservatism (Crowson et al., 2005), but that authoritarians often obey nonconservative social norms while living in liberal environments. For example, in societies where pro-environmental norms are widely shared, authoritarian submissiveness is related to stronger pro-environmental beliefs (Reese, 2012). Similarly, in societies where public expression of hate speech is legally banned, authoritarians object to the idea of decriminalizing hate speech, even if they personally agree with the hateful comments (Bilewicz et al., 2017). Furthermore, authoritarians living among people with pro-Jewish attitudes express lower levels of antisemitism than the rest of the population, while authoritarians living in a nonhomophobic environment are less likely to support collective action against the LGBT rights (Górska et al., 2021). In the ethnically diverse environments, authoritarians engage in more contact with minority groups and express higher levels of trust to minorities, relative to authoritarians in less ethnically diverse areas (van Assche et al., 2019; Brune et al., 2016). Based on these findings one could expect that people high on right-wing authoritarianism should be more likely to vaccinate, as long as the vaccination norm is endorsed by the leaders and authorities.

The Dual Process Model of Ideology highlights also another aspect of authoritarianism that might be relevant to vaccination attitudes - a belief that the world is a threatening and dangerous place (Duckitt \& Sibley, 2010). Research on right-wing authoritarianism has found that people high on RWA consider the world to 
be full of dangers and seek to defend themselves and others against them (Altemeyer, 1981; Altemeyer, 1996). As a result, authoritarians develop prejudice toward those outgroups whom they consider to be threatening, but not toward those who are seen as just competitive (Cohrs \& Asbrock, 2009; Cohrs \& Ibler, 2009). Authoritarians also report more fears, especially those related to unconventional situations and individuals (Eigenberger, 1998). This threat-related aspect of authoritarianism should motivate people high on RWA to support vaccination as a means to collectively respond to the threat of epidemic disease.

The empirical studies looking at authoritarianism and vaccination hesitancy are relatively rare, and in most of them, RWA has not been considered a main variable of interest. One study has found authoritarianism to be positively related with vaccine hesitancy and resistance in Ireland, but not in the UK (Murphy et al., 2021). An American study performed during the Donald J. Trump's presidency has found a positive correlation between right-wing authoritarianism and anti-vaccination attitudes (Kempthorne \& Terrizi, 2021). In these studies, however, the effects of authoritarianism were assessed without controlling for other related ideological variables. Such an approach could confound authoritarianism with a more general conservative orientation. A more fine-grained analysis could examine the factual impact of authoritarianism on vaccination hesitancy.

\section{The Anti-Egalitarian Aspects of Social Dominance Orientation}

Since their beginnings, universal vaccination programs aimed at providing equal access to immunisation against infectious diseases. The egalitarian character of public healthcare has often been a target of criticism in conservative and rightwing milieus (cf. Saldin, 2010). The particular facet of right-wing ideology that is responsible for such anti-egalitarian objections is known as social dominance 
orientation - a belief-system that supports group hierarchies and justifies existing inequalities (Pratto et al., 1994; Sidanius \& Pratto, 1999).

The Dual Process Model of Ideology suggests that social dominance orientation is a consequence of a belief that the world is a competitive jungle in which "the strong" win and "the weak" lose (a "dog-eat-dog" view of society; Duckitt \& Sibley, 2009). Indeed, longitudinal studies have shown that the degree to which the word is perceived as competitive is a positive predictor of social dominance orientation, but not of right-wing authoritarianism (Sibley et al., 2007). Moreover, SDO has been found to predict prejudice toward groups who are viewed as exploiting the ingroup or being of low status (but not those seen as competitive, Cohrs \& Asbrock, 2009). The goal of this motivation is not to elicit competition, but rather to maintain the inequality.

The COVID-19 pandemic has not only been a global public health issue but has also exacerbated the existing global inequalities. The COVID-19-associated mortality rates differed between the rich and poor countries, and between the wealthy and the impoverished populations within countries (Ahmed et al., 2020). Countries with dysfunctional healthcare systems have been particularly helpless in the face of the pandemic. A universal vaccination program against COVID-19 has been seen as an obvious way to counteract these striking healthcare inequalities by providing immunity to all people, regardless of their status. This could pose a threat to people high in SDO, who are motivated to main inequalities. However, this is just one of the mechanisms linking high SDO to higher vaccine hesitancy.

Although a tendency to believe in conspiracy theories is visible on both extremes of the political spectrum, several specific conspiracy theories are endorsed more by the right-wing supporters (van Prooijen et al., 2015). A recent study looking 
at correlates of people's beliefs in conspiracy theories has found that both RWA and SDO are positive predictors of such beliefs, however SDO is a stronger predictor than RWA (Dyrendal et al., 2021). In the context of the COVID-19 pandemic, people high in SDO have been found to be more willing to share pandemic-related misinformation (especially conspiracy theories) on social media platforms (Lobato et al., 2020). The fact that conspiracy theories often focus on revealing the competition between hidden powerful forces, which supposedly drive any important political event or social process, makes people high on SDO particularly prone to interpret reality using such theories.

Therefore, social dominance orientation is clearly an aspect of right-wing ideology that could contribute to vaccination hesitancy. As any vaccination program is egalitarian and universal, it violates the principle of inequality that is at the core of social dominators' belief system. Moreover, people high on SDO should be more sceptical about vaccination programs due to their tendency to believe in conspiracy theories.

\section{The Ideological Dual-Process Model Approach to Vaccine Hesitancy}

The Ideological Dual-Process Model approach to vaccine hesitancy takes into account the essential differences between the two aspects of right-wing ideology. In the times of the COVID-19 pandemic, vaccination has become a widely shared norm in most societies, both in the descriptive (the majority of people in most countries are in favour of vaccination) as well as in the prescriptive sense (the majority of scientific, religious and political authorities support vaccination efforts; for the description of different types of social norms, see, Brauer \& Chaurand, 2010). Therefore, we predict that in the times of the global pandemic authoritarianism will be linked to 
higher acceptance of vaccination, as people high on RWA tend to follow group norms and directives from the authorities.

On the other hand, vaccination is contested by a loud and visible minority who believe in conspiracy theories about potential hidden risks of vaccines and expect that the governments will impose compulsory vaccination on their societies. People high on SDO oppose government interventions, particularly those that reduce societal wealth disparities. Free universal vaccination violates the essence of their worldview, and therefore it can be expected that people high on SDO would express higher vaccination hesitancy.

\section{The Current Study}

In order to test our hypotheses, we conducted a large international study of vaccination intentions in three countries: Germany, Poland, and the United Kingdom. The main aim was to test the roles of SDO and RWA in predicting vaccination hesitancy, as well as cross-cultural universality of the pattern of relationships between political ideologies and attitudes toward vaccines.

\section{Method}

All data, questionnaires, and analysis scripts are available on the Open Science Framework ([MASKED]). The data were collected as a part of a larger project not related to vaccine hesitancy. The research project was approved by the University of [MASKED] Research Ethics Board (NUMBER). Only the variables directly related to the research question are reported here.

\section{Participants}

Participants in all three countries (Germany, $N=1210$; Poland, $N=1209$; UK, $N=1222$ ) were recruited online. A quota-representative sampling based on gender, age, and education distributions in each country was adopted. The data collection 
took place between April 7th and April 14th, 2021. Out of the total sample, 124 individuals were excluded from the analysis because of unreliable responses (i.e., age higher than 100 years, more than 24 years of education, number of years of education greater than the person's age). The remaining sample consisted of 1688 men, 1801 women, and 28 individuals who declared their gender as other. The participants were aged from 19 to 89 years $\left(M_{\text {age }}=46.80, S D_{\text {age }}=15.90\right)$. Their level of education measured in years of formal education ranged from 0 to 24 years $(M$ educ. $\left.=12.10, S D_{\text {educ. }}=5.28\right)$.

While planning sample sizes, we chose typical values used in nationally representative surveys (i.e., 1000 participants per country). We did not conduct a priori power analysis. However, we conducted a sensitivity power analysis (with a significance criterion, $\alpha=.05$, power criterion of $80 \%$, and a final sample size of 3517) to obtain a minimal detectable effect size for a comparison of linear regression models with 7 and 9 predictors. This analysis yielded a value of $\Delta R^{2}=.003^{1}$. Thus, the final size was sufficient to detect even very small effects.

\section{Measures}

\section{Right-Wing Authoritarianism (RWA)}

To measure RWA, we used a short version of the right-wing authoritarianism scale developed by Beierlein et al. (2014). The scale consists of 9 items (e.g., Rules in society should be enforced without pity) capturing the three components of RWA: aggression, submission, and conventionalism. Participants indicated the extent to which they agreed with each statement using a 5-point Likert scale ranging from 1 (Definitely disagree) to 5 (Definitely agree). Internal consistency of the scale was

\footnotetext{
${ }^{1}$ Power analysis in the case of Bayesian statistics as well as with more advanced models is still under development. Thus, despite using Bayesian hierarchical models, we conducted the power analysis for frequentist linear regression. Therefore, the obtained result only approximates the correct value.
} 
satisfactory in all three countries (Germany, $\alpha=.86$; Poland, $\alpha=.86$; UK, $\alpha=.86$ ).

See Table 1 for means and standard deviations.

\section{Social Dominance Orientation (SDO)}

SDO was measured with a scale developed by Pratto et al. (2006), adapted by Bilewicz et al. (2014). The scale consists of 5 items (e.g., Groups on top should dominate groups at the bottom). Participants indicated their answers on a 5-point scale identical to the one used for the RWA items. Internal consistency of the scale was satisfactory across the three countries (Germany, $\alpha=.79$; Poland, $\alpha=.77$; the UK, $\alpha=.81)$. See Table 1 for descriptive statistics.

\section{Intentions to Vaccinate Against COVID-19}

Intentions to vaccinate against COVID-19 were measured by asking participants whether they would be willing to take the vaccine in two potential scenarios. In the first case, the vaccination program was presented as compulsory and in the second case as voluntary (i.e., Would you agree to take the vaccine against COVID-19 if the inoculations were compulsory/voluntary?). Participants indicated their answers on a 5-point scale ranging from 1 (Definitely not) to 5 (Definitely yes). Percentages of response options indicated for each question are presented in Table 1.

\section{Table 1}

Descriptive statistics for the predictor and outcome variables in the study

\begin{tabular}{lccr}
\hline Measures & Germany & Poland & UK \\
\hline RWA & $3.00(0.81)$ & $3.17(0.81)$ & $3.12(0.77)$ \\
SDO & $2.19(0.85)$ & $2.34(0.83)$ & $2.21(0.86)$
\end{tabular}


Intentions to vaccinate

(compulsory vaccinations)

Definitely not

Rather not

Don't know

Rather yes

Definitely yes

52.64

35.08

Intentions to vaccinate

(voluntary vaccinations)

Definitely not

Rather not

Don't know

Rather yes

Definitely yes
10.63
17.36

9.08

17.63

67.26

Note. For continuous measures values are $M(S D)$. For ordinal measures values are percentages of participants indicating a specific answer.

\section{Results}

The outcome variables of interest were intentions to vaccinate against COVID-19 in two hypothetical scenarios - vaccinations being compulsory or voluntary. Rather than aggregating the two variables into a single indicator, we decided to use hierarchical modelling to predict participants' responses in each scenario. Moreover, rather than assuming that these variables are continuous and Normal, we decided to treat them as ordinal. Thus, we fitted two Bayesian 
hierarchical ordinal regression models using R package brms (Bürkner, 2017). We chose the cumulative family function for the outcome variables and decided to use the brms's default weakly informative priors for the model parameters. Continuous predictors were standardized before including in the model, and sum-contrasts coding was used for categorical predictors. The posterior samples of 4000 postwarmup draws indicated no problems with convergence (Rhat $<1.01$, bulk-ESS $<$ 331, tail-ESS < 604, 0 divergent transitions).

Within the first model (see left side of Table 2), intentions to vaccinate were regressed on gender (men vs. women vs. other), age, education, country of residence (Germany vs. Poland vs. UK), and vaccine policy (compulsory vs. voluntary). As indicated by the $R^{2}$ coefficient, Model 1 explained a large proportion of the outcome variables.

Further analyses revealed that individuals from Poland had overall lower intentions to vaccinate against COVID-19 than individuals from Germany, $\Psi=-2.23$, $95 \% \mathrm{Cl}(-2.76,-1.67), \mathrm{OR}=0.11$, and the UK, $\psi=-3.89,95 \% \mathrm{Cl}(-4.38,-3.34), \mathrm{OR}=$ 0.02. Moreover, individuals from the UK had higher intentions to vaccinate than individuals from Germany, $\psi=1.66,95 \% \mathrm{Cl}(1.08,2.23), \mathrm{OR}=5.25$. In addition, men had higher intentions to vaccinate than women, $\psi=0.55,95 \% \mathrm{Cl}(0,13,0.93)$, $\mathrm{OR}=1.73$. Intentions to vaccinate were also positively correlated with participants' age and years of education. The former effect was large, and the latter was small. Finally, there was almost no difference in responses to questions about compulsory versus voluntary vaccination policy, $\psi=0.03,95 \% \mathrm{Cl}(-0.09,0.16), \mathrm{OR}=1.03 . \mathrm{In}$ other words, individuals reported similar levels of readiness to be vaccinated against COVID-19 irrespective of whether the vaccination would be compulsory or voluntary. 


\section{Table 2}

Summary of the two Bayesian hierarchical ordinal models of intentions to vaccinate regressed on the demographic variables, RWA, and SDO

\begin{tabular}{|c|c|c|c|c|c|c|c|c|}
\hline \multirow[b]{3}{*}{ Parameter } & \multicolumn{4}{|c|}{ Model 1} & \multicolumn{4}{|c|}{ Model 2} \\
\hline & \multirow{2}{*}{ estimate } & \multicolumn{2}{|c|}{$95 \% \mathrm{Cl}$} & \multirow{2}{*}{ OR } & \multirow{2}{*}{ estimate } & \multicolumn{2}{|c|}{$95 \% \mathrm{Cl}$} & \multirow{2}{*}{ OR } \\
\hline & & LL & UL & & & LL & UL & \\
\hline & \multicolumn{8}{|c|}{ Fixed effects } \\
\hline $\mathrm{T}_{1}$ & -7.74 & -8.57 & -6.92 & & -7.84 & -8.69 & -6.97 & \\
\hline $\mathrm{T}_{2}$ & -6.03 & -6.84 & -5.23 & & -6.14 & -7.00 & -5.32 & \\
\hline $\mathrm{T}_{3}$ & -3.04 & -3.82 & -2.27 & & -3.15 & -3.98 & -2.34 & \\
\hline $\mathrm{T}_{4}$ & -0.40 & -1.16 & 0.37 & & -0.50 & -1.31 & 0.29 & \\
\hline \multicolumn{9}{|l|}{ Gender } \\
\hline men & 0.12 & -0.64 & 0.93 & 1.13 & 0.16 & -0.64 & 0.96 & 1.18 \\
\hline $\begin{array}{l}\text { women } \\
\text { other }\end{array}$ & -0.41 & -1.19 & 0.37 & 0.66 & -0.63 & -1.44 & 0.19 & 0.53 \\
\hline Age & 1.89 & 1.67 & 2.12 & 6.62 & 1.78 & 1.56 & 2.01 & 5.91 \\
\hline Education & 0.37 & 0.16 & 0.58 & 1.45 & 0.38 & 0.18 & 0.57 & 1.46 \\
\hline \multicolumn{9}{|l|}{ Country } \\
\hline Poland & -2.19 & -2.49 & -1.89 & 0.11 & -2.20 & -2.50 & -1.92 & 0.11 \\
\hline UK & 2.02 & 1.71 & 2.34 & 7.57 & 2.04 & 1.74 & 2.35 & 7.71 \\
\hline \multicolumn{9}{|l|}{ Germany } \\
\hline Vaccine policy & & & & & & & & \\
\hline $\begin{array}{l}\text { compulsory } \\
\text { voluntary }\end{array}$ & 0.01 & -0.05 & 0.07 & 1.01 & 0.01 & -0.05 & 0.07 & 1.01 \\
\hline RWA & & & & & 0.37 & 0.14 & 0.58 & 1.44 \\
\hline SDO & & & & & -0.82 & -1.06 & -0.59 & 0.44 \\
\hline
\end{tabular}

Random effects

Level 2
Intercept $(\sigma)$
$\begin{array}{lll}5.34 & 5.04 & 5.67\end{array}$
$5.3 \quad 5.01 \quad 5.62$

$R^{2}$ 
LOOIC

11093.6

11084.5

Note. $\mathrm{Cl}=$ credible intervals, $\mathrm{LL}=$ lower limit, UP = upper limit, OR = odds ratio, LOOIC = leave-one-out information criterion. $T_{n}$ refers to specific thresholds of the ordinal regression model. Parameter estimates for categorical predictors refer to their distances from the sample means. Categories with empty rows are treated as reference points and as fixed (specific pairwise comparisons are described in the text).

In the next step of the analysis, measures of RWA and SDO were added as predictors of intentions to vaccinate (see right side of Table 2). This resulted in a model with higher predictive accuracy (expressed by lower values of LOOIC) than Model, and with slightly larger $R^{2}$. Including the two predictors did not affect the main conclusions of Model 1. With all other variables held constant, individuals with high SDO had lower intentions to vaccinate against COVID-19 than those with low SDO. The model-estimated probability of the relationship being negative indicated high certainty $\left(p_{D}=100 \%\right)$, and the size of this relationship (expressed in Cohen's $d$ ) was moderate, $d=-0.45$ (according to the interpretation by Lovakov and Agadulina, 2021). At the same time, with all other variables kept constant, participants with high RWA had higher intentions to vaccinate than individuals with low RWA. The size of this relationship was small, $d=0.20$ (according to the interpretation by Lovakov and Agadulina, 2021), but the model-estimated probability of this relationship being positive indicated high certainty $\left(p_{D}=100 \%\right)$.

\section{Discussion}

Previous research has yielded mixed evidence for the relationship between right-wing ideology and attitudes toward COVID-19 vaccination (Callaghan et al., 2020; Hornsey et al., 2020; Hornsey et al., 2021; Kennedy, 2019; Kossowska et al., 
2021). We applied the Dual-Process Model of Ideology (Duckitt, 2001; Duckitt \& Sibley, 2009) in order to further our understanding of the role of ideological factors in explaining people's intentions to vaccinate against COVID-19. The Dual-Process Model of Ideology distinguishes between two forms of right-wing ideology - one stressing the natural character of power and hierarchies (SDO), and another one stressing social control and group conformity (RWA). We hypothesised that these two components would differentially predict intentions to vaccinate. Specifically, we expected that RWA would be positively associated with intentions to vaccinate, whereas SDO would be negatively associated with such intentions.

We conducted a large-scale investigation of our hypotheses across three countries: Poland, the United Kingdom, and Germany. In all of our analyses, we controlled for the potential confounding effects of gender, age, and education. Our analyses revealed that both components of right-wing ideology (RWA and SDO) were significant predictors of intentions to vaccinate against COVID-19, but the direction of these relationship was different. In all three countries, high SDO was associated with higher vaccine hesitancy, whereas high RWA was associated with lower vaccine hesitancy. While the sizes of these relationships were moderate and small, respectively, the model indicated that it is almost certain that their directions differed. Therefore, the study results confirmed our hypotheses.

This novel finding is an important contribution to our understanding of the nature of right-wing ideology, right-wing authoritarianism in particular. Upon its conceptualization, RWA was presented as a factor responsible for antisemitic prejudice and submissiveness (Adorno et al., 1951) that led to the atrocities of the Second World War. For a long time, this has shaped our understanding of RWA and drawn researchers' attention to its negative aspects. However, recent empirical 
studies seem to seem to provide a more balanced perspective on RWA. High-RWA individuals are not always the ones who are highly prejudiced. In fact, in social contexts that promote diversity, inclusiveness, and peaceful coexistence, high-RWA individuals have lower levels of prejudice, engage in more contact with minority groups, express higher levels of trust to minorities, and oppose public expression of prejudice more strongly than low-RWA individuals (Bilewicz et al., 2017; Brune et al., 2016; Górska et al., 2021; van Assche et al., 2019). Positive aspects of RWA go beyond intergroup relations. For example, those with high RWA seem to care more about the natural environment and express stronger environmental beliefs than those with low RWA (Reese, 2012). Overall, growing body of research seems to present high-RWA individuals as guardians caring for the wellbeing of the collective. Our findings fit perfectly with this perspective. As getting vaccinated is a way of protecting not only oneself but also others in one's environment, and thus of improving the well-being of the society as a whole, it should resonate with high-RWA individuals.

Furthermore, our findings contribute to our understanding of the nature of social dominance orientation. However, in this case, they provide a confirmation for the destructive role of this aspect of right-wing ideology. Perceiving the world as a competitive jungle seems to stand in contrast with caring for the wellbeing of the society. Fuelled by the omnipresent anti-vaccine conspiracy theories, high-SDO individuals can view vaccination as a mean to being dominated rather than dominating, and perhaps as an act of admitting their ingroup's weakness. Thus, high-SDO individuals seem to value the image of their group as powerful and the existing hierarchies more than the well-being of their ingroup members.

\section{Limitations and Future Directions}


Unfortunately, the study did not inquire whether participants had already received a COVID-19 vaccine. By April 14th, 18.5 percent of the German population, 16.4 percent of the Polish population, and 48.9 percent of the British population had received at least one dose of a COVID-19 vaccine. Thus, it is likely that at the time of the study some participants, at least in the case of the UK sample, had already been vaccinated. However, the vaccination program in all three countries was voluntary. Therefore, we do not believe that the fact that some participants had already been vaccinated could have an effect on the results indicating the role of RWA and SDO in promoting vaccine acceptance. It may however explain the differences observed between the three countries: The highest intentions to vaccinate reported by the UK participants may have resulted from the fact that the UK had had the highest percentage of individuals vaccinated at the time of the study (those already vaccinated are likely to have expressed the highest intentions to vaccinate).

We also acknowledge that although we conducted our study in three countries, it is definitely not enough to ascertain whether the observed pattern of results is universal across different cultures or states. Particularly, the relationship between RWA and attitudes toward vaccination may be different in countries where leaders voice anti-vaccine sentiments, deny the existence of the COVID-19 pandemic, or diminish its consequences. In fact, in such countries, high RWA should be associated with higher levels of vaccine hesitancy. There, those who warn against actions contributing to COVID-19 surges and promote vaccination programs may be labelled by the country leaders as dissidents and troublemakers, which may, in turn, fuel anti-vaccine attitudes among high-RWA individuals. Future large-scale cross-cultural studies should examine this hypothesis. 
As any concerns surrounding one's decision to vaccinate might lead to a delay in the vaccination process and therefore, threaten public health, future studies should investigate how to utilize the knowledge about the ideological basis of vaccine hesitancy. Specifically, research should examine what arguments should be used to persuade individuals with both high and low RWA, and both high and low SDO. For example, we proposed that individuals with high SDO might have a tendency to endorse anti-vaccine conspiracy theories to a greater extent than individuals with low SDO. This suggestion is yet to be verified, but we believe that steps should be taken to investigate how to inoculate high-SDO individuals against the destructive effects of conspiracy theories. Moreover, forcing low-RWA individuals to vaccinate may threaten their core value of autonomy and lead to higher vaccine hesitancy. Thus, efforts should be made to design vaccination campaigns or policies that address this specific problem by, perhaps, portraying vaccines as a mean to improve one's autonomy.

\section{References}

Adorno, T. W., Frenkel-Brunswik, E., Levinson, D. J., \& Sanford, R. N. (1951). The authoritarian personality. Harper \& Row.

Ahmed, F., Ahmed, N., Pissarides, C., \& Stiglitz, J. (2020). Why inequality could spread COVID-19. The Lancet Public Health, 5(5).

https://doi.org/10.1016/s2468-2667(20)30085-2

Altemeyer, B. (1981). Right-wing authoritarianism. University of Manitoba Press Altemeyer, B. (1996). The authoritarian specter. Harvard University Press.

Altemeyer, B. (1998). The other "authoritarian personality". Advances in Experimental Social Psychology, 30, 47-92. https://doi.org/10.1016/S00652601(08)60382-2 
Beierlein, C., Asbrock, F., Kauff, M., \& Schmidt, P. (2014). Die Kurzskala Autoritarismus-3 (KSA-3): Ein ökonomisches messinstrument zur erfassung dreier subdimensionen autoritärer einstellungen [A short scale for measuring three dimensions of authoritarianism] (GESIS Working Papers). GESIS.

Bilewicz, M., Marchlewska, M., Soral, \& W., Winiewski, M. (2014). Hate speech in Poland 2014. Summary of the national opinion poll. Stefan Batory Foundation.

Bilewicz, M., Soral, W., Marchlewska, M., \& Winiewski, M. (2017). When authoritarians confront prejudice. Differential effects of SDO and RWA on support for hate-speech prohibition. Political Psychology, 38(1), 87-99. https://doi.org/10.1111/pops.12313

Brauer, M., \& Chaurand, N. (2010). Descriptive norms, prescriptive norms, and social control: An intercultural comparison of people's reactions to uncivil behaviors. European Journal of Social Psychology, 40(3), 490-499. https://doi.org/10.1002/ejsp.640

Brune, A., Asbrock, F., \& Sibley, C. G. (2016). Meet your neighbours. Authoritarians engage in intergroup contact when they have the ppportunity. Community \& Applied Social Psychology, 26(6), 567-580. https://doi.org/10.1002/casp.2289

Bürkner, P. C. (2017). brms: An R package for Bayesian multilevel models using Stan. Journal of Statistical Software, 80(1), 1-28. https://doi.org/10.18637/jss.v080.i01

Callaghan, T., Moghtaderi, A., Lueck, J. A., Hotez, P. J., Strych, U., Dor, A., Fowler, E. F., \& Motta, M. (2020). Correlates and disparities of COVID-19 vaccine hesitancy. https://ssrn.com/abstract=3667971 https://dx.doi.org/10.2139/ssrn.3667971 
Cisłak, A., Marchlewska, M., Wojcik, A. D., Śliwiński, K., Molenda, Z., Szczepańska, D., Cichocka, A. (in press) National narcissism and support for anti-vaccination policy: The mediating role of vaccination conspiracy beliefs. Group Processes and Intergroup Relations.

Cohrs, J. C., \& Asbrock, F. (2009). Right-wing authoritarianism, social dominance orientation and prejudice against threatening and competitive ethnic groups. European Journal of Social Psychology, 39(2), 270-289. https://doi.org/10.1002/ejsp.545

Cohrs, J. C., \& Ibler, S. (2009). Authoritarianism, threat, and prejudice: An analysis of mediation and moderation. Basic and Applied Social Psychology, 31(1), 8194. https://doi.org/10.1080/01973530802659638

Crowson, H. M., Thoma, S.J., \& Hestevold, N. (2005). Is political conservatism synonymous with authoritarianism? The Journal of Social Psychology, 145(5), 571-592. https://doi.org/10.3200/SOCP.145.5.571-592

Dube, E., Laberge, C., Guay, M., Bramadat, P., Roy, R., \& Bettinger, J. a. (2013). Vaccine hesitancy. Human Vaccines \& Immunotherapeutics, 9(8), 1763-1773. https://doi.org/10.4161/hv.24657

Duckitt, J. (2001). A dual-process cognitive-motivational theory of ideology and prejudice. Advances in Experimental Social Psychology, 33, 41-113. https://doi.org/10.1016/S0065-2601(01)80004-6

Duckit, J., \& Sibley, C. G. (2009). A Dual-Process Motivational Model of ideology, politics, and prejudice. Psychological Inquiry, 20(2), 98-109. https://doi.org/10.1080/10478400903028540 
Duckitt, J., \& Sibley, C. G. (2010). Personality, ideology, prejudice, and politics: A Dual-Process Motivational Model. Journal of Personality, 78(6), 1861-1894. https://doi.org/10.1111/j.1467-6494.2010.00672.x

Dyrendal, A., Kennair, L. E. O., Bendixen, M. (2021). Predictors of belief in conspiracy theory: The role of individual differences in schizotypal traits, paranormal beliefs, social dominance orientation, right wing authoritarianism and conspiracy mentality. Personality and Individual Differences, 173. https://doi.org/10.1016/j.paid.2021.110645

Eigenberger, M. E. (1998). Fear as a correlate of authoritarianism. Psychological Reports, 83(3), 1395-1409. https://doi.org/10.2466/pr0.1998.83.3f.1395

Feldman, S. (2003). Values, ideology, and the structure of political attitudes. In D. O. Sears, L. Huddy, \& R. Jervis (Eds.), Oxford handbook of political psychology (p. 477-508). Oxford University Press.

Fridman, A., Gershon, R., \& Gneezy, A. (2021). COVID-19 and vaccine hesitancy: A longitudinal study. PLOS ONE, 16(4).

https://doi.org/10.1371/journal.pone.0250123

Górska, P., Stefaniak, A., Lipowska, K., Malinowska, K., Skrodzka, M., \& Marchlewska, M. (2021), Authoritarians go with the flow: Social norms moderate the link between right-wing authoritarianism and outgroup-directed attitudes. Political Psychology. https://doi.org/10.1111/pops.12744

Hornsey, M. J., Finlayson, M., Chatwood, G., \& Begeny, C. T. (2020). Donald Trump and vaccination: The effect of political identity, conspiracist ideation and presidential tweets on vaccine hesitancy. Journal of Experimental Social Psychology, 88. https://doi.org/10.1016/j.jesp.2019.103947 
Hornsey, M. J., Champan, C. M., Alvarez, B., Bentley, S., Casara, B. G. S., Crimston, C. R., Ionescu, O., Krug, H., Selvanathan, H. P., Steffens, \& N. K., Jetten, J. (2021). To what extent are conspiracy theorists concerned for self versus others? A COVID-19 test case. European Journal of Social Psychology, 1-9. https://doi.org/10.1002/ejsp.2737

Jarrett, C., Wilson, R., O’Leary, M., Eckersberger, E., \& Larson, H. J. (2015). Strategies for addressing vaccine hesitancy - A systematic review. Vaccine, 33(34), 4180-4190. https://doi.org/10.1016/j.vaccine.2015.04.040

Jost, J., Federico, C., M., \& Napier, J. L. (2009). Political Ideology: Its Structure, Functions, and Elective Affinities. Annual Review of Psychology, 60, 307-337. https://doi.org/10.1146/annurev.psych.60.110707.163600

Jost, J. T., Glaser, J., Kruglanski, A. W., \& Sulloway, F. J. (2003). Exceptions that prove the rule--Using a theory of motivated social cognition to account for ideological incongruities and political anomalies: Reply to Greenberg and Jonas (2003). Psychological Bulletin, 129(3), 383-393. https://doi.org/10.1037/00332909.129.3.383

Kempthorne, J. C., \& Terrizzi, J. A. (2021). The behavioral immune system and conservatism as predictors of disease-avoidant attitudes during the COVID-19 pandemic. Personality and Individual Differences, 178. https://doi.org/10.1016/j.paid.2021.110857 Kennedy, J. (2019). Populist politics and vaccine hesitancy in Western Europe: an analysis of national-level data. European Journal of Public Health, 29(3), 512516. https://doi.org/10.1093/eurpub/ckz004 
Kossowska, M., Szwed, P., \& Czarnek, G. (2021, February 3). Ideology shapes trust in scientists and attitudes towards vaccines during the COVID-19 pandemic. https://doi.org/10.31234/osf.io/hcbmw

Lobato, E. J. C., Powell, M., Padilla, L. M. K., \& Holbrook, C. (2020). Factors predicting willingness to share COVID-19 misinformation. Frontiers in Psychology, 11. https://dx.doi.org/10.3389\%2Ffpsyg.2020.566108

MacDonald, N. E. (2015). Vaccine hesitancy: Definition, scope and determinants. Vaccine, 33(34), 4161-4164. https://doi.org/10.1016/j.vaccine.2015.04.036 Murphy, J., Vallières, F., Bentall, R. P., Shevlin, M., McBride, O., Hartman, T. K., McKay, R., Bennett, K., Mason, L., Gibson-Miller, J., Levita, L., Martinez, A. P., Stocks, T. V. A., Karatzias, T., \& Hyland, P. (2021). Psychological characteristics associated with COVID-19 vaccine hesitancy and resistance in Ireland and the United Kingdom. Nature Communications, 12(29), 1-15. https://doi.org/10.1038/s41467-020-20226-9

Pratto, F., Sidanius, J., \& Levin, S. (2006). Social dominance theory and the dynamics of intergroup relations: Taking stock and looking forward. European Review of Social Psychology, 17(1), 271-320.

https://doi.org/10.1080/10463280601055772

Pratto, F., Sidanius, J., Stallworth, L. M., \& Malle, B. F. (1994). Social dominance orientation: A personality variable predicting social and political attitudes. Journal of Personality and Social Psychology, 67(4), 741-763. https://doi.org/10.1037/0022-3514.67.4.741

Reese, G. (2012). When authoritarians protect the earth-authoritarian submission and proenvironmental beliefs: A pilot study in Germany. Ecopsychology, 4(3). https://doi.org/10.1089/eco.2012.0035 
Saldin, R. P. (2010). Healthcare reform: A prescription for the 2010 Republican landslide? The Forum, 8(4). https://doi.org/10.2202/1540-8884.1404

Sibley, C. G., Wilson, M. S., \& Duckitt, J. (2007). Antecedents of men's hostile and benevolent Sexism: The dual roles of social dominance orientation and rightwing authoritarianism. Personality and Social Psychology Bulletin, 33(2), 160172. https://doi.org/10.1177/0146167206294745

Sibley, C. G., \& Duckitt, J. (2008). Personality and prejudice: A meta-analysis and theoretical review. Personality and Social Psychology Review, 12(3), 248-279. https://doi.org/10.1177/1088868308319226

Sidanius, J., \& Pratto, F. (1999). Social dominance: An intergroup theory of social hierarchy and oppression. Cambridge University Press.

Van Assche, J., Roets, A., Van Hiel, A., \& Dhont, K. (2019). Diverse reactions to ethnic diversity: The role of individual differences in authoritarianism. Current Directions in Psychological Science, 28(6), 523-527. https://doi.org/10.1177/0963721419857769

Van Prooijen, J. W., Krouwel, A. P. M., \& Pollet, T. V. (2015). Political extremism predicts belief in conspiracy theories. Social Psychological and Personality Science, 6(5), 570-578. https://doi.org/10.1177/1948550614567356 